\title{
Effects of Cooked Starches and Sucrose or their Combination on Salivary $\alpha$-Amylase Activity and Oral $\mathrm{pH}$
}

\author{
Wafaa Abdelraouf Khalil ${ }^{1}$, Mohamed Yusuf Sukkar², Bakri G Gismalla ${ }^{3}$ \\ ${ }^{1}$ Basic Sciences Department, Faculty of Dentistry, Khartoum University \\ ${ }^{2}$ Physiology Department, Faculty of Medicine, Khartoum University \\ ${ }^{3}$ Periodontal Department, Faculty of Dentistry, Khartoum University
}

\begin{abstract}
There are many questions about starch, sucrose and their combination in increasing the cariogencity of dental plaque flora biofilm. This research aimed at evaluating the activity of salivary a-amylase and oral $\mathrm{pH}$, in the presence of either sucrose or cooked starches compared with when both are used together. Sixty adult males, who fulfilled the inclusion criteria according to a structured questioner interviews to assess their dental hygiene and nutritional habits, were recruited for the study, their salivary and dental plaque a-amylase activity and $\mathrm{pH}$ measurement were assessed.Higher activity of salivary and dental plaque a-amylase and lower pH were reported in the group who ate a meal containing cooked starches plus intake of sucrose in the form of soft drinks or sugared tea, compared to those subjects who only took sugars or a meal containing cooked starches. Results suggest that cooked starches when followed with sugars produce a stronger effect on salivary $\alpha$ - amylase activity and in lowering oral pH, thus proposing an increased cariogenic activity of starch and sucrose combination.
\end{abstract}

Keywords: Cooked Starches, Sucrose, Salivary $\alpha$-amylase Activity, Oral pH, Cariogencity, Plaque biofilm

\section{Introduction}

Sucrose is considered the most cariogenic dietary carbohydrate due to its role in synthesis of extracellular glucans, ${ }^{(1)}$ while starches were suggested to be slightly cariogenic when taken as the only source of carbohydrate in diet. ${ }^{(2)}$ Recent studies have suggested thata combination of soluble starch with sucrose might be more cariogenic than sucrose alone. ${ }^{(3)}$ This synergistic effect could be explained bystarch fermentation by the bound dental plaque $\alpha$-amylase enzyme and the enhancement of formation of polysaccharides which are used as an energy sourceby the microbes, ${ }^{(4)}$ which further secure their attachment to the pellicle-coated enamel, and also forming one of the stable components in any mature biofilm, the extracellular matrix. ${ }^{(5,6)}$ The extracellular matrix retains nutrients and water and allows nutrients to pass these in between the channels to other microbes in the community, ${ }^{(7)}$ which encourages acids to accumulate in the Streptococcus mutansbiofilm. ${ }^{(8,9)}$ Despite these findings, however, the role of starch in increasing the cariogenic potential of the plaque flora biofilm in the presence of sucrose has being recently questioned. $\left({ }^{10,11)}\right.$ This study therefore aims at evaluating the effect either sucrose or cooked starches compared with their combination together on salivary $\alpha$-amylase activity and oral $\mathrm{pH}$.

\section{Subjects and Methods}

\section{Study Design}

In this retrospective observational study, sixty adult male volunteers were selected for the study onbasis of structured questioner interviews to assess their oral hygiene. According to the questioner, they were to be excluded from the study (exclusion criteria) if they had a known chronic illness, recent antibiotic medications and if they were on regularintake of caffeine (more than once daily). Their nutritional habits assessment included asking them about their recent intake, within the last 1-4 hours before conducting the interview and performing the tests, of a meal containing cooked starches and sugary sucrose component, whereby they were categorized into two groups: those who had cooked starches followed immediately by sugared tea or drinks (combination of cooked starches with sucrose), and those who had either soft sugary drinks (sucrose) or a cooked starchy meal.

\section{Study Procedures}

Saliva Sample Collection: Approximately $3 \mathrm{ml}$ of spitted whole mouth saliva was collected from the selected study subjects. Paraffin wax was chewed for 2 minutes as a stimulant after rinsing the mouth with water; collected saliva from each subject carried in a $15 \mathrm{ml}$ graduated centrifuge tubes, in an ice box to be stored at $-20^{\circ} \mathrm{C}$.

Dental Plaque Sample Collection: Immediately after saliva collection, plaque samples were carefully scaled supragingivally upon the selected teeth using sterilized dental curettes. The plaque sample was then transferred immediately to $1.5 \mathrm{ml}$ Eppendorf tubes containing $0.5 \mathrm{ml}$ of purified distilled water (water for injection) and transported in an ice box to be stored at $-20^{\circ} \mathrm{C}$.

Salivary and dental plaque $\alpha$ - amylase enzyme measurement:

Salivary $\alpha$ - amylase enzyme assay method: On the day of the specified $\alpha$-amylase assay, stored saliva samples were cold centrifuged at $2000 \mathrm{rpm}$ for 15 minutes. $1 \mathrm{ml}$ of clear 


\section{International Journal of Science and Research (IJSR) ISSN (Online): 2319-7064 \\ Index Copernicus Value (2013): 6.14 | Impact Factor (2014): 5.611}

sample was transferred to $0.5 \mathrm{ml}$ Eppendorf tube, for salivary $\alpha$-amylase enzyme assay. Salivary $\alpha$-amylase assay Kit (Catalog No.1-1902) is specially designed for the kinetic measurement of salivary $\alpha$ - amylase activity. ${ }^{(12)}$ The mean of duplicated absorbance read and the absorbance difference/minute was calculated. $\alpha$ - amylase activity was calculated according to a formula provided by the Kit (Fisher Scientific America). Levels are considered in this study according to the Kit high and low controls. Low $\alpha$ - amylase activity was found to be $<39 \mathrm{u} / \mathrm{ml} /$ minute, moderate activity $=39-108 \mathrm{u} / / \mathrm{ml} /$ minute and high activity $=>108 \mathrm{u} / \mathrm{ml} / \mathrm{min}$. Absolute range in this study was $14-$ $400 \mathrm{u} / \mathrm{ml} /$ minute; Reference range ${ }^{(12)}$ : Adult range, $(\mathrm{n}=75)$ mean $=92.4 \mathrm{u} / \mathrm{ml}$, absolute range $=3.1-423.1 \mathrm{U} / \mathrm{mL}$

Plaque $\boldsymbol{\alpha}$-amylase measurement: Stored dental plaque samples in $0.5 \mathrm{ml}$ purified distilled water, were weighed using a sensitive balance. Standard dental plaque mass of about $0.05 \mathrm{gm}$ was chosen. Dental plaque samples were vortexed for 1 minute and then centrifuged at 2000rpm for 15 minutes. A sensitive balance was used for weighing: (Denver instrument company)/caloric weight variance (100-12.2mg). The clear supernatant was transferred, to $1.5 \mathrm{ml}$ Eppendorf tubes, ready for alpha amylase measurement as for salivary amylase measurement. The same salivary $\alpha$-amylase assay kit was used for the dental plaque $\alpha$-amylase enzyme activity assay. The dilution step (3) in the Kit was cancelled. Another step was added including preparing standard dental plaque mass around $0.05 \mathrm{gm}$ in $0.5 \mathrm{ml}$ of purified distilled water and hence another dilution factor and concentration had been put into consideration. Absolute range obtained for dental plaque $\alpha$ amylase in grams in this study was $0.03-5 \times 10^{3} \mathrm{u} / \mathrm{gm} /$ minute (no reference for this range).

Ethical Issues: All participants of the study signed an informed consent form. There is no conflict of interests observed, all authors have seen and approved the manuscript being submitted.

\section{Results}

Significant higher activity of salivary amylase was noted on the eleven individuals who reported to have taken a meal composed of cooked starchesfollowed by taking a sugary drink, compared to its activity in individuals who had taken either a meal containing cooked starches not followed with sugars or sugars alone without starchy meal( $p$-value $=0.012$ and 0.014 respectively)[Table 1]. Similarly significant higher activity of dental plaque $\alpha$ - amylase reported after a meal composed of cooked starches-containing mealfollowed with sugars when compared with its activity with a starchy or a sugary intake only ( $\mathrm{p}$-value $=0.020$ and 0.004 respectively)[Table 2].A significant lowering in salivary $\mathrm{pH}$ following a meal composed of cooked starches followed by taking a sugary drink is observed, when compared with the $\mathrm{pH}$ following a meal containing a starchy component not followed by a sugary drink $(p$-value $=0.000)$ [Table 3 ].

Table 1: Comparing the effect of a meal type on salivary $\alpha$ - amylase activity:

\begin{tabular}{|c|c|c|c|c|c|c|}
\hline \multirow{2}{*}{ Meal components } & \multicolumn{4}{|c|}{ Salivary $\alpha$ - amylase $(\mathrm{u} / \mathrm{ml} / \mathrm{min})$} & \multicolumn{3}{c|}{ Salivary $\alpha$ - amylase $(\mathrm{u} / \mathrm{ml} / \mathrm{min})$} \\
\cline { 2 - 7 } & $\mathrm{N}$ & Mean $\pm \mathrm{SD}$ & Meal components & $\mathrm{N}$ & Mean \pm SD & $\mathrm{p}$-value \\
\hline A meal containing starch & 43 & $114.23 \pm 68.44$ & Sugars & 6 & $86.16 \pm 44.28$ & 0.353 \\
\hline A meal containing starch +sugars & 11 & $176.70 \pm 80.31$ & Protein+ lipid+ starch & 43 & $114.23 \pm 68.44$ & $\underline{0.012}$ \\
\hline Sugars & 6 & $86.16 \pm 44.28$ & Protein, lipid +starch + sugars & 10 & $176.70 \pm 80.31$ & $\underline{0.014}$ \\
\hline
\end{tabular}

Table 2: Comparing the effect of a meal type on plaque $\alpha$ - amylase activity:

\begin{tabular}{|c|c|c|c|c|c|c|}
\hline \multirow{2}{*}{ Meal components } & & \multicolumn{2}{|c|}{ plaque amylase(u/gm/min $)$} & \multicolumn{3}{|c|}{ plaque amylase(u/gm/min) } \\
\hline & $\mathrm{N}$ & Mean \pm SD & Meal components & $\mathrm{N}$ & Mean \pm SD & p-value \\
\hline A meal containing starch & 43 & $2.003 \pm 1.475$ & sugars & 6 & $0.530 \pm 0.381$ & $\underline{0.020}$ \\
\hline A meal containing starch + sugars & 11 & $2.704 \pm 1.451$ & Protein+ lipid + starch & 43 & $2.003 \pm 1.475$ & 0.147 \\
\hline Sugars & 6 & $0.530 \pm 0.381$ & Protein + lipid + starch + sugars & 11 & $2.704 \pm 1.451$ & $\underline{0.004}$ \\
\hline
\end{tabular}

Table 3: Comparing the effect of a meal type on salivary $\mathrm{pH}$

\begin{tabular}{|c|c|c|c|c|c|c|}
\hline \multirow{2}{*}{ Meal components } & & \multicolumn{2}{|c|}{ Saliva $\mathrm{pH}$} & \multicolumn{2}{c|}{ Saliva $\mathrm{pH}$} \\
\cline { 2 - 7 } & $\mathrm{N}$ & Mean \pm SD & Meal components & $\mathrm{N}$ & Mean \pm SD & $\mathrm{p}$-value \\
\hline A meal containing starch & 43 & $7.89 \pm 0.52$ & sugars & 6 & $7.58 \pm 0.29$ & 0.153 \\
\hline A meal containing starch + sugars & 11 & $7.23 \pm 0.42$ & Protein+ lipid+ starch & 43 & $7.89 \pm 0.52$ & $\underline{0.000}$ \\
\hline Sugars & 6 & $7.58 \pm 0.29$ & Protein+ lipid+ starch + sugars & 10 & $7.23 \pm 0.42$ & 0.169 \\
\hline
\end{tabular}

A possible relationship was detected between the activity of salivary $\alpha$-amylase and salivary and dental plaque pH when related to meal type Fig.[1-3] 
International Journal of Science and Research (IJSR)

ISSN (Online): 2319-7064

Index Copernicus Value (2013): 6.14 | Impact Factor (2014): 5.611

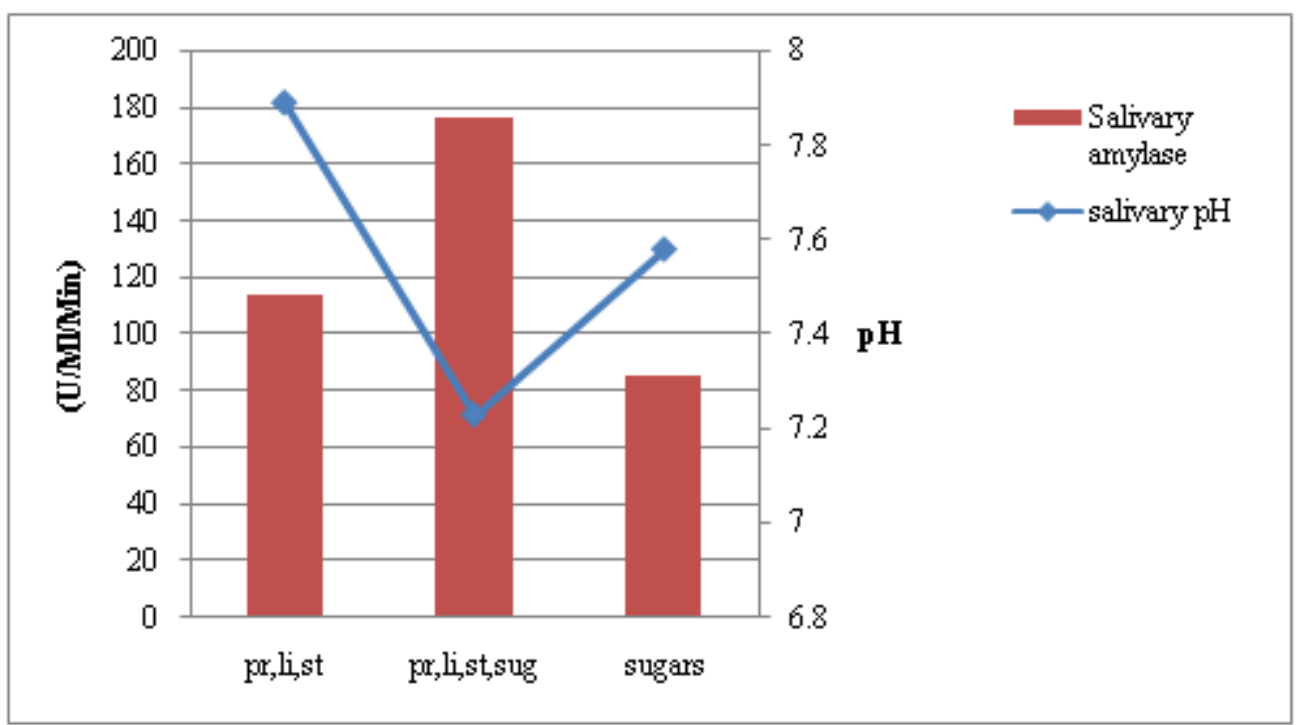

Figure 1: Relationship of salivary $\alpha$-amylase with salivary $\mathrm{pH}$ when related to meal type

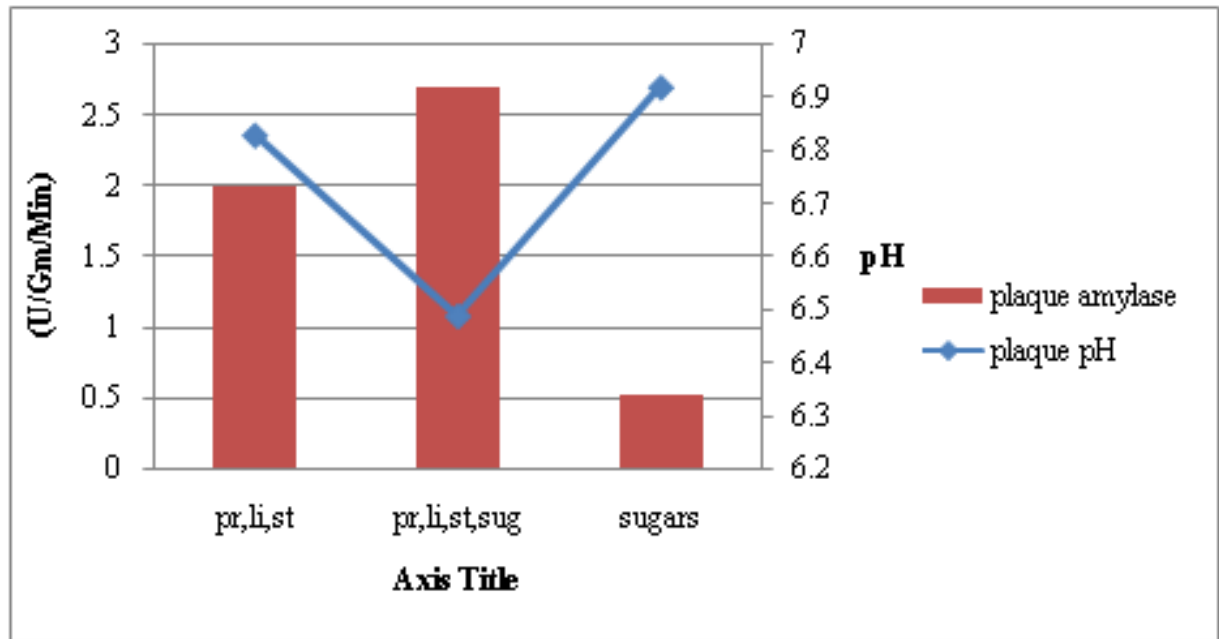

Figure 2: Relationship of plaque $\alpha$-amylase enzyme activity with plaque $\mathrm{pH}$ when related to meal type

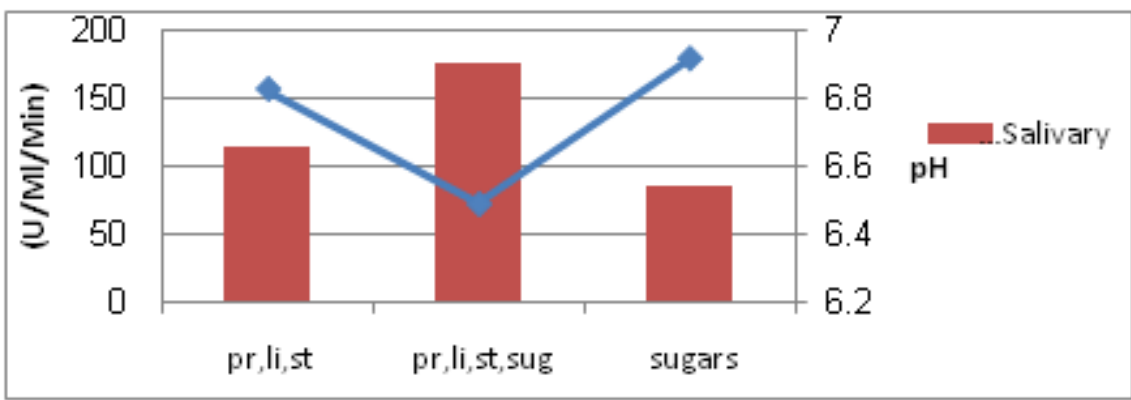

Figure 3: Relationship of salivary $\alpha$ - amylase activity with plaque $\mathrm{pH}$ when related to meal type

\section{Discussion}

The role of starch in increasing the cariogenic potential of the plaque flora biofilm in the presence of sucrose has being recently questioned. $\left.{ }^{(10,11}\right)$ Our findings, however, support this cariogenicity of starch, as such going in line with those studies that suggest the synergetic combination of starch and sucrose in causing dental caries by increasing the activity of salivary $\alpha$-amylase. ${ }^{(12)}$ Dodds and Edgar have suggested that starch fermentation may be enhanced by prior plaque exposure to sucrose. ${ }^{(13)}$ Bowen also suggested that sweetened starches were more cariogenic in rats than just sucrose alone. ${ }^{(14)}$ Others explained these observations by the synergistic effect between starch and sucrose or that cooked or sweetened starches are more sticky and retentive than sucrose alone. ${ }^{(15)}$ In the light of these observations, a synergistic effect between sucrose and starch may be suggested to be due to the enhanced fermentation of starch by plaque -bound $\alpha$ - amylase with a subsequent increase in caries activity. Significant lowering of $\mathrm{pH}$ with starch in the presence of sucrose observed in our research, is also supported by Lingstromet al, ${ }^{(16)}$, who, when testing the effect of a series of processed starch and sucrose on plaque $\mathrm{pH}$, found that glucose and sucrose reference solution showed the greatest $\mathrm{pH}$ drop in the plaque. 


\section{International Journal of Science and Research (IJSR) \\ ISSN (Online): 2319-7064}

Index Copernicus Value (2013): 6.14 | Impact Factor (2014): 5.611

\section{Conclusion}

It is to be concluded that synergistic effect exists between cooked starches and sucrose on salivary and dental plaque $\alpha$-amylase activity, and that a drop of salivary and dental plaque $\mathrm{pH}$ aftercombination of cooked starches and sucrose is due probably to the higher salivary amylase activity, thus suggestingan increased risk of dental caries with combination of cooked starches and sucrose, an observation that might have an important nutritional implication in the preventive strategies against dental plaque and caries formation.

\section{References}

[1] Rolla G, Scheie AA, Ciardi JE: Role of sucrose inplaque formation. Scand J Dent Res 1985; 93:105111.

[2] Lingstrom P, van Houte J, Kashket S: Foodstarches and dental caries. Crit Rev Oral BiolMed 2000; 11: 366-380.

[3] Ribeiro CC, Tabchoury CP, Del Bel Cury AA, TenutaLM, Rosalen PL, Cury JA: Effect of starchon the cariogenic potential of sucrose. Br JNutr 2005; 94: 44-50.

[4] Burnett and Schuster. Text book of oral microbiology and infectious disease. USA, 1962 ;ed.2: Section IV.

[5] Gibbons, R. and Houte, J. "Bacterial Adherence in Oral Microbial Ecology." Annual Reviews. Microbiology 1975; 29:19-42

[6] Marsh. P. Dental Plaque as a microbial biofilm. Caries Research. 2004; 38:204-211

[7] Jacob M.Ten Cat. Biofilm, a new approach to the microbiology of dental plaque.Odonto-logy 2006; 94(1)

[8] Kopec LK, Vacca-Smith AM, Bowen WH: Structuralaspects of glucans formed in solutionand on the surface of hydroxyapatite. Glycobiology 1997; 7 : 929-934

[9] Duarte S, Klein MI, Aires CP, Cury JA, BowenWH, Koo H. Influences of starch and sucroseon Streptococcus mutansbiofilms. Oral Microbiol Immunol 2008; 23: 206-212

[10] Thurnheer T, Giertsen E, Gmür R, GuggenheimB: Cariogenicity of soluble starch in oral invitro biofilm and experimental rat cariesstudies: a comparison. J ApplMicrobiol 2008(in press).

[11] C.P. Aires a A.A. Del Bel Cury a L.M.A. Tenuta a M.I. Klein b H. Koo b S. Duarte b J.A. Cury a. Effect of Starch and Sucrose on DentalBiofilm Formation and on Root DentineDemineralization, Caries Res 2008;42:380-386

[12] Wallenfels, K., Foldi, P., Niermann, H., Bender, H., Linder, D. The enzymic synthesis, by transglucosylation of a homologous series of glycosidically substituted malto-oligosaccharides, and their use as alpha- amylase substrates. Carbohydrate Research.1978; 61: 359-368.

[13] Dodds, M. W. J. and W. M. Edgar: Effects of Dietary Sucrose Levels on $\mathrm{pH}$ Fall and Acid-Anion Profile in Human Dental Plaque after a Starch Mouthrinse. Arch. Oral Biol. 1986; 31:509.
[14] Bowen, W. H., S. M. Amsbaugh, S. Monell-Torrens, J. Brunelle, H. uzimak-Jones, and M. F. A. Cole: A Method to Assess Cariogenic Potential of Foodstuffs. J. Am. Dent. Assoc. 1981;100:677-681.

[15] Scannapieco F.A., Torres G.I., and Levine M.J.. Salivary alpha Amylase: role in dental plaque and caries formation, Critical Reviews in oral biology and medicine, 1993; 4: 301-307.

[16]LINGSTROM P., Holm J., Birkled1 D. \&BJORCK J. Effects of variousity of processed starch, on $\mathrm{pH}$ of human dental plaque. European Journal of oral science. 1989; 97(5): 392-400 